\title{
¿QUIÉNES VIAJABAN? INVESTIGANDO LA MUERTE DE VIAJEROS PREHISPÁNICOS EN EL DESIERTO DE ATACAMA (CA. 800 AC-1536 DC)
}

\author{
Christina Torres-Rouff, ${ }^{12}$ Gonzalo Pimentel ${ }^{3}$ y Mariana Ugarte ${ }^{4}$
}

\section{* Introducción}

\section{Resumen}

Históricamente, los estudios de movilidad en los Andes se han centrado en el modelo caravanero, según el cual fueron grupos de hombres de tierras altas, con sus recuas de llamas, los agentes encargados del tráfico interregional. Se presenta aquí el análisis de nueve contextos mortuorios excavados a lo largo de senderos prehispánicos que conectaron la desembocadura del río Loa con los oasis de Tarapacá (Guatacondo y Pica) y con el área atacameña (Quillagua y Calama), que nos entregan una perspectiva individualizada sobre quienes realizaban estos exigentes viajes. Nuestro estudio viene a ampliar la idea de

Pimentel y colaboradores (2011a) de que existieron distintas estrategias de movilidad en el desierto de Atacama, incluyendo una modalidad costera de acceso directo a los oasis de valles bajos. Se describen las tumbas de hombres, mujeres y niños demostrando la existencia de nuevas modalidades de circulación entre la costa y el interior en el desierto de Atacama.

Palabras claves: movilidad - bioarqueología - osteobiografía - caravanas.

\begin{abstract}
Historically, studies of mobility in the Andes have focused on a caravan model, where the regional flows of people and goods depended on the movement of groups of men seeking resources unavailable in the highlands. Here we present the results of our excavation and analysis of nine individuals from tombs along prehistoric routes connecting the mouth of the Loa River to the Tarapacá oases (Guatacondo and Pica) and the Atacameño area (Quillagua y Calama), which allow for a human perspective on human mobility. Our research supports and builds on Pimentel and colleagues (2011a) recent contention that there were multiple modes of mobility in northern Chile's Atacama Desert, including a coastal modality for access to the interior valleys and oases. Here, we document the burial of men, women, and children, suggesting the existence of varied modes of movement between the coast and the interior in the post-archaic Atacama.
\end{abstract}

Key words: mobility - bioarchaeology - osteobiography - caravans.
Durante décadas, la movilidad de grupos humanos prehispánicos ha sido parte central de las investigaciones arqueológicas en el área andina, enfocadas principalmente desde la perspectiva de la complementariedad de pisos ecológicos. Estos modelos, integrados a la discusión arqueológica por Murra $(1972,1985)$ y posteriormente por Browman (1980, 1984), y Núñez y Dillehay (1995 [1979]; Dillehay y Núñez 1988), han enfatizado la necesidad de las poblaciones de tierras altas de adquirir bienes deseados pero no disponibles en su área, enfocando los estudios hacia sus asentamientos nucleares y sus "colonias" ubicadas en diferentes nichos ecológicos. Es así que, frecuentemente, se ha perdido de vista la agencia de aquellos grupos que habitaban fuera de los territorios de tierras altas y se ha prestado solo una mínima atención a las vías y "espacios vacíos" que forman la estructura esqueletal de su argumento, aunque cada vez están más presentes en las investigaciones sobre la movilidad preincaica (p.e. Núñez et al. 2003; Berenguer 2004; Nielsen 2006; Pimentel 2006; Núñez y Nielsen 2011).

Para el mundo andino en general y específicamente para el desierto de Atacama, hay temas no resueltos y escasamente comprendidos sobre los agentes dedicados a realizar los largos viajes. ¿Quiénes eran los encargados de realizar los viajes transdesérticos?, ¿era una actividad que recaía solo en determinadas sociedades, eran grupos especializados de una sociedad o era una actividad generalizada a todos los agentes y sociedades? La arqueología, la etnohistoria y la etnografía andina han respondido en

Recibido: marzo 2012. Aceptado: octubre 2012.

\footnotetext{
1 Instituto de Investigaciones Arqueológicas y Museo, Universidad Católica del Norte, San Pedro de Atacama, 141-0000, CHILE. Email: ctorres@ucn.cl
} 
parte a estas cuestiones, prevaleciendo interdisciplinariamente la idea de que fueron las poblaciones de tierras altas (pastoriles y agropastoriles) las encargadas de conectar los distintos pisos ecológicos y con ello de promover las relaciones de intercambio. Esto se formalizó como el modelo caravanero (Browman 1980, 1984; Núñez y Dillehay 1995 [1979]), que concibe un movimiento dirigido desde tierras altas hacia ambas vertientes de la cordillera de los Andes, vale decir, tanto hacia la costa Pacífica como hacia las yungas orientales. Al ser poblaciones que contaban con el único animal domesticado en los Andes destinado al transporte de cargas (Llama, Lama glama), se le ha otorgado una mayor visibilidad histórica a su rol en la circulación y el intercambio, con un bajo nivel de reconocimiento de la movilidad de otras poblaciones como las costeras y selváticas.

Nuestro objetivo en este artículo es contribuir al debate, centrándonos en la pregunta de quiénes realizaban los viajes largos en el pasado. Para esto, documentamos aquí los contextos de nueve individuos enterrados a lo largo de un conjunto de vías prehispánicas que conectaban la costa con el interior en el norte de Chile. Utilizando un enfoque bioarqueológico, esperamos poder ofrecer una perspectiva innovadora sobre la movilidad en el pasado, poniendo en relieve a los agentes específicos que dieron vida a la circulación transversal de personas y productos en el desierto de Atacama.

\section{* Contribuciones de la arqueología vial}

Las redes viales en cuanto son una manifestación directa de la movilidad, nos permiten visualizar la red efectiva de conexiones intra e interregionales, brindando una imagen de integridad, continuidad y unidad de un amplio territorio sobre las relacionales entre grupos humanos espacialmente distanciados pero socialmente vinculados notablemente entre sí. Mantener activas las relaciones

\footnotetext{
2 Department of Anthropology, University of California, Merced, 5200 N. Lake Road, Merced, California, 95343, EE.UU. Email: ctorres-rouff@ucmerced.edu

3 Instituto de Investigaciones Arqueológicas y Museo, Universidad Católica del Norte, San Pedro de Atacama, 141-00oo, CHILE. Email: gpimentel@ucn.cl

4 Arqueonorte Ltda., Santa Victoria 45, Santiago, CHILE. Email: mugarte@arqueonorte.cl
}

de intercambio societales implicó necesariamente el movimiento de gente y bienes por las vías de tránsito, por lo que si hay una condición obligatoria, intermediaria y de gran envergadura en todo este proceso, es la de la circulación y el transporte. Tal como lo han hecho notar distintos autores, al ser las redes viales el resultado de estrategias tecnológicas, políticas, económicas y simbólicas de toda sociedad, su estudio nos proporciona información de primer nivel para lograr un acercamiento a las estrategias de interacción y la organización social (Earle 1991; Trombold 1991; Erickson 2000).

La imagen prevaleciente que nos muestra la etnografía andina es que la movilidad caravanera estaba organizada al nivel de las unidades productivas domésticas, conformada por pequeños grupos que integraban a los hombres de la familia o con relación de compadrazgo. Aunque las caravanas incaicas parecen haber tenido tamaños considerables, con un centenar o más de llamas y numerosos hombres, datos etnográficos presentan un modelo que podría representar más de cerca el patrón preincaico en el área atacameña, en el que grupos pequeños viajaban con una docena de animales. Estos extensos desplazamientos con recuas de llamas podían durar desde varios días hasta varios meses, recorriéndose distancias que alcanzaban entre los 20 a $30 \mathrm{~km}$ diarios. Las recuas de llamas, por su parte, la componían animales machos que eran castrados y adiestrados especialmente para tales fines, pudiendo cargar cada uno normalmente entre 20 y $30 \mathrm{~kg}$, y hasta un máximo de $46 \mathrm{~kg}$ (Browman 1974; Casaverde 1977; Flores Ochoa 1977; Inamura 1986; Lecoq 1987; Göbel 1998; Nielsen 1997, 2001). De acuerdo a la etnografía, por lo tanto, se trataba de una actividad altamente especializada que comprometía exclusivamente a los hombres del grupo base.

La arqueología surandina ha demostrado que los viajes caravaneros ya estaban plenamente consolidados a lo menos hace 3500 años. Desde el inicio del período Formativo existen evidencias claras de que los viajes caravaneros fueron efectivamente una estrategia altamente consolidada (Cartajena 1994; Núñez y Dillehay 1995 [1979]; Nielsen 2006; Pimentel 2008). Recientemente se ha podido ampliar el modelo para el desierto de Atacama, determinándose que, junto con una modalidad caravanera, funcionó sincrónicamente otra estrategia que tuvo objetivos, intereses y alcances diferenciados. Es lo que se sintetizó como 


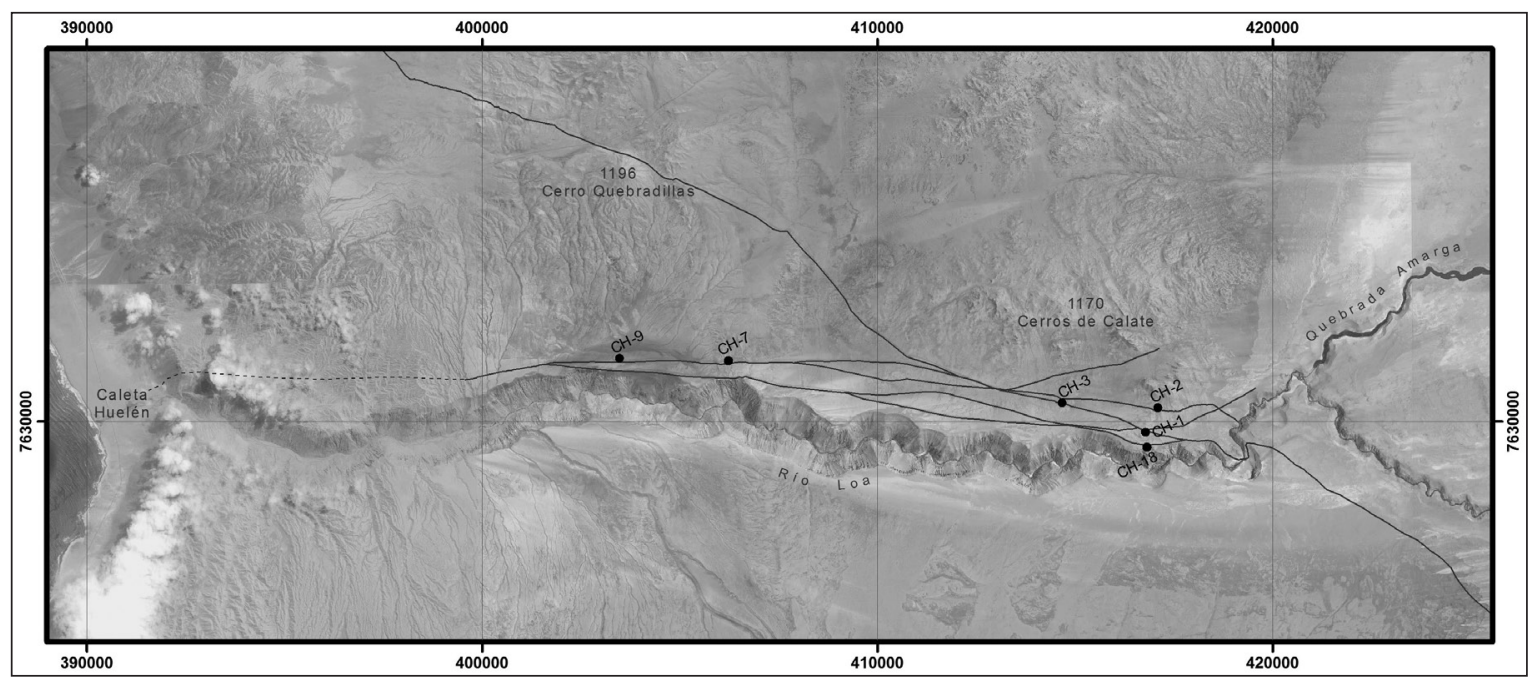

Figura 1. Mapa del área de estudio, con los sitios mencionados en el texto y las rutas que conectaron la desembocadura del río Loa y la confluencia con Quebrada Amarga.

una modalidad costera promovida por poblaciones procedentes del litoral Pacífico y que accedían hasta el interior (Depresión Intermedia y oasis de valles bajos) con el objetivo principal de aprovisionarse directamente de determinados recursos (líticos y vegetales), bajo una estrategia logística y con un alcance espacial restringido (Pimentel et al. 2010a, 2011a). Las evidencias de los senderos, campamentos de descanso y del entierro circunstancial de un viajero costero masculino del formativo en la Depresión Intermedia, fueron consistentes en precisar que las poblaciones costeras tuvieron también su propio sistema de movilidad multidireccional, lo que además sugería que eran igualmente los hombres los encargados exclusivos de realizar estos viajes desde la costa hacia el interior (Cases et al. 2008; Pimentel et al. 2011; Knudson et al. 2012).

En el presente artículo presentamos el análisis de nueve viajeros que fueron enterrados a la vera de senderos prehispánicos en el desierto absoluto de Atacama, en el sector de Calate, los cuales muestran una sugerente diversidad que nos permite contrastar y ampliar la discusión sobre las modalidades de movilidad y sus agentes. Esta muestra de viajeros prehispánicos que fallecieron en pleno tránsito y que cubren un rango temporal que abarca desde el Formativo Temprano hasta el período Inka (ca. $821 \mathrm{AC}-1536 \mathrm{DC}$ ), resulta de alta relevancia para responder más fehacientemente la pregunta sobre las características de los viajeros, y especialmente sobre sus condiciones biológicas, origen zonal, sexo y perfil etario.

\section{* El caso de estudio: Calate}

El sector de Calate se ubica en la actual frontera entre la Región de Antofagasta y Tarapacá, donde el río Loa confluye con la Quebrada Amarga y se produce el desvío final de su cauce hacia el poniente (Figura 1). Corresponde a una planicie desértica con sectores de arenales, carcanales y de limo suelto, cruzada por serranías bajas y cerros islas, siendo los cerros de Calate los más altos de toda el área (1.170 m.s.n.m.). En términos de las conexiones viales, en este sector se entrecruzan distintos senderos prehispánicos que conectaban tanto el área atacameña, vía Quillagua, como también el área tarapaqueña con Caleta Huelén en la costa (desembocadura del río Loa). Esta posición geográfica vial privilegiada de Calate, donde confluyeron viajeros procedentes a lo menos de la costa, Tarapacá y Atacama, constituyó el motivo principal para analizar sistemáticamente el sector y con ello abordar las diferencias temporales y culturales de los viajeros prehispánicos en el desierto de Atacama.

En el tramo vial que va desde la confluencia de Quebrada Amarga con el Loa hasta Caleta Huelén, identificamos 
28 sitios arqueológicos que dan cuenta de la movilidad entre la costa y el interior desde el Arcaico Medio hasta los períodos tardíos (Tabla 1). Se reconocieron sitios monofuncionales $(n=17)$, algunos de ellos exclusivamente habitacionales $(n=8)$, geoglifos y grabados $(n=4)$, posibles tumbas $(n=3)$, estructuras ceremoniales $(n=1)$ y de señalización $(n=1)$. Los otros casos corresponden a sitios multifuncionales $(\mathrm{n}=11)$, que compartieron diferencialmente en una misma locación actividades habitacionales con estructuras ceremoniales, o bien con representaciones rupestres y/o con tumbas (Pimentel 2009; Pimentel et al. 2010b). Es dentro de este último grupo que se encuentra el conjunto de contextos mortuorios que aquí analizamos.

\section{* Contribuciones de la perspectiva BIOARQUEOLÓGICA}

La bioarqueología se define como el estudio contextual de los restos humanos recuperados de sitios arqueológicos (Buikstra y Beck 2006). Basándose históricamente en los análisis médicos sobre esqueletos, la bioarqueología contemporánea se ha expandido más allá de la biología y es una práctica multidisciplinaria que se centra en la fuerte incorporación de la información cultural proveniente de los contextos arqueológicos, con el fin de relacionar mejor a los individuos con sus experiencias vividas. Dentro de las corrientes bioarqueológicas contemporáneas (Buikstra et al. 2011: 9), destacamos el marco osteobiográfico inicialmente defendido por Saul (1972) y más tarde desarrollado por Robb (2002) para estudiar al ser humano durante el curso de la vida. Saul (1972: 8) propone reconstruir la historia de vida registrada en los huesos a partir de un análisis detallado de la vida de los individuos (p.e. Stodder y Palkovich 2012). Las osteobiografías frecuentemente toman la forma de descripciones exhaustivas y bien contextualizadas de los esqueletos individuales, intentando además en muchos trabajos contemporáneos, entender la relación entre los procesos biológicos y sus interpretaciones culturales al nivel de los individuos (Boutin 2011). Esta perspectiva nos permitirá aprehender de manera más integrada la vida y las características principales de los viajeros.

En el presente trabajo combinamos los enfoques de la arqueología vial con la osteobiografía para explorar la vida de nueve individuos enterrados en el área de Calate, a partir de las cuales realizaremos un análisis más contextualizado de los viajeros postarcaicos del desierto de Atacama.

\section{* Métodos bioarqueológicos}

Las perspectivas bioarqueológicas y osteobiográficas nos brindan una oportunidad de lograr un acercamiento privilegiado a nivel del individuo o el agente mismo que fallece en el ejercicio del viaje. Para el análisis bioarqueológico de los restos óseos, nos centramos en cuatro elementos específicos: características demográficas, modificación del cráneo, patologías (incluyendo lesiones traumáticas) y contexto del entierro. La recopilación de datos para los restos óseos se basó en protocolos estándar (Buikstra y Ubelaker 1994; Steckel y Rose 2002; Buzon et al. 2005). El sexo fue determinado principalmente sobre la base de las características dimórficas del cráneo y pelvis y la asignación etaria fue otorgada en base a la morfología de la sínfisis pubiana y el grado de fusión de las suturas craneanas (Buikstra y Ubelaker 1994), dando preferencia a la primera cuando presente. Para los niños, la edad se determinó en base al desarrollo dental, fusión de las epífisis y medición de los huesos largos (Buikstra y Ubelaker 1994). Es necesario precisar que la variabilidad tanto en el estado de conservación de los individuos como en las regiones anatómicas presentes en cada entierro no permitió en algunos casos la recolección de todos los datos.

La importancia del estudio de las modificaciones craneanas radica en su uso como expresión visible de distinciones sociales (p.e. Torres-Rouff 2002, 2008; Blom 2005). Se examinaron los cráneos para identificar modificaciones intencionales en su forma mediante cintas o almohadillas rígidas, práctica que se ha vinculado a distintos grupos sociales. Aquellos cráneos que carecían de signos claros de alteración deliberada se calificaron como sin modificación, ya que es probable que las variaciones pequeñas en su forma, aunque visibles en el esqueleto, no fuesen detectables a través de la piel y del pelo en las personas vivas. Los individuos que presentaron alteraciones más prominentes se agruparon en categorías amplias, basadas en una modificación de las definiciones propuestas originalmente por Dembo e Imbelloni (1938): circular (circunferencial) o tabular (fronto-occipital) con sus 
¿Quiénes Viajaban? InVestigando la muerte de viajeros prehispánicos en el desierto de Atacama...

\begin{tabular}{|c|c|c|c|c|c|c|c|c|c|c|}
\hline \multirow[b]{2}{*}{$\begin{array}{l}\text { Código } \\
\text { Sitio }\end{array}$} & \multirow{2}{*}{$\begin{array}{c}\text { Arte Rupestre } \\
\text { Geoglifos }\end{array}$} & \multicolumn{4}{|c|}{ Estructuras Ceremoniales } & \multicolumn{2}{|c|}{ Evidencia Habitacional } & \multirow[b]{2}{*}{ Tumbas } & \multirow[b]{2}{*}{$\begin{array}{l}\text { Componentes } \\
\text { Cerámicos }\end{array}$} & \multirow[b]{2}{*}{$\begin{array}{l}\text { Cronología } \\
\text { Relativa } \\
\text { (Período) }\end{array}$} \\
\hline & & $\begin{array}{c}\text { Líneas de } \\
\text { piedra }\end{array}$ & $\begin{array}{c}\text { Amontonamientos } \\
\text { irregulares }\end{array}$ & $\begin{array}{l}\text { Estructura } \\
\text { monticular }\end{array}$ & Sepulcro & Estructuras & Depresiones & & & \\
\hline $\mathrm{CH}-1$ & $\mathrm{x}$ & $\mathrm{x}$ & $\mathrm{x}$ & & & $\mathrm{x}$ & & 2 & Loa - San Pedro & \begin{tabular}{|l|} 
Formativo Tardío/ \\
Intermedio Tardío \\
- Tardio/ Histórico \\
\end{tabular} \\
\hline $\mathrm{CH}-2$ & & $\mathrm{x}$ & $\mathrm{x}$ & & & $\mathrm{x}$ & & 2 & Loa - San Pedro & $\begin{array}{c}\text { Formativo Tardío/ } \\
\text { Intermedio Tardío } \\
\text { - Tardío }\end{array}$ \\
\hline $\mathrm{CH}-3$ Sur & & $\mathrm{x}$ & $\mathrm{x}$ & & & $\mathrm{x}$ & & 1 & $\begin{array}{c}\text { Tarapacá- Loa } \\
\text { Inferior / NOA// } \\
\text { Loa-San Pedro/ } \\
\text { Altiplano Meridional }\end{array}$ & $\begin{array}{c}\text { Formativo Tardío/ } \\
\text { Intermedio Tardío } \\
\text { - Tardío }\end{array}$ \\
\hline $\begin{array}{l}\mathrm{CH}-3 \\
\text { Norte }\end{array}$ & & $\mathrm{x}$ & $\mathrm{x}$ & & & $\mathrm{x}$ & & 1 & $\begin{array}{c}\text { Tarapacá - Loa } \\
\text { Inferior/Loa - San } \\
\text { Pedro/Altiplano } \\
\text { Meridional }\end{array}$ & $\begin{array}{c}\text { Formativo Tardío/ } \\
\text { Intermedio Tardío } \\
\text { - Tardío }\end{array}$ \\
\hline $\mathrm{CH}-7$ & $\mathrm{x}$ & $\mathrm{x}$ & $\mathrm{x}$ & & & $\mathrm{x}$ & & 1 & $\begin{array}{l}\text { Tarapacá - Loa } \\
\text { Inferior/ } \\
\text { Loa - San Pedro }\end{array}$ & $\begin{array}{c}\text { Formativo Tardío/ } \\
\text { Intermedio Tardío } \\
\text { - Tardío }\end{array}$ \\
\hline $\mathrm{CH}-9$ & & & & & & $\mathrm{x}$ & $\mathrm{x}$ & 2 & \begin{tabular}{|c} 
Loa - San Pedro/ \\
Tarapacá - Loa \\
Inferior - Altiplano \\
Meridional/ Costero \\
(Taltal - Cobija)
\end{tabular} & $\begin{array}{l}\text { Formativo Tardío? } \\
\text { Intermedio Tardío } \\
\text { - Tardío/ Histórico }\end{array}$ \\
\hline $\mathrm{CH}-18$ & & & $\mathrm{x}$ & & & & & 1 & & \\
\hline
\end{tabular}

Tabla 1. Detalles de los sitios con contextos mortuorios excavados en el sector de Calate.

variantes erecta u oblicua; la constricción circunferencial que resulta en la deformación circular produce un cráneo alargado y estrecho, mientras que la modificación tabular crea una compresión anteroposterior que, además, resulta en la expansión lateral de la cabeza. Probablemente ambos tipos de modificación craneana eran visiblemente diferentes en el individuo vivo.

A pesar de existir una variabilidad significativa al interior de estas categorías más amplias, los grandes tipos reflejan diferencias estructurales en la práctica y marcan el acto intencional de modificar la forma de la cabeza, permitiendo simplificar el análisis clasificando visualmente las cabezas en formas de cráneos alargados o ensanchados. Estas diferencias se han relacionado tradicionalmente con ciertas áreas geográficas. Por ejemplo, el uso de las deformaciones circulares en el área de los Chinchorro y en el altiplano boliviano (Marroquín 1944; Arriaza 1995), mientras que las formas tabulares son las más comunes en el interior del desierto chileno (Torres-Rouff 2007). Estas asociaciones, sin embargo, no son absolutas sino solo representan tendencias, ya que son muchos los luga- res donde se encuentran ambas formas entre grupos que vivieron y se enterraron juntos sus muertos.

Se documentaron a su vez todas las evidencias de patologías. Esto incluyó datos como la presencia de osteoartritis, probablemente debido en parte al uso constante del cuerpo durante largos viajes, y las lesiones traumáticas que pudiesen mostrar eventos de violencia y accidentes a lo largo de la vida de un individuo o durante sus últimos momentos mientras transitaba estas rutas. Las heridas fueron documentadas con referencia a su tamaño, ubicación y estado de la cicatrización (Buikstra y Ubelaker 1994; Walker 1989; Larsen 1999). En cuanto al tipo de lesiones, el trauma en el esqueleto post-craneano se asocia frecuentemente con lesiones accidentales o estrés laboral (Walker 1989; Neves et al. 1999; Standen y Arriaza 2000), siendo común este tipo de fracturas en poblaciones que ocupan terrenos peligrosos. Por otro lado, tanto los traumatismos craneanos como las heridas defensivas, además de los signos de traumas causados por armas, proporcionan las evidencias más fuertes de violencia interpersonal (Walker 1989), de modo que 


\begin{tabular}{|c|c|c|c|c|c|}
\hline Individuo & Sexo & Edad & Posible lugar de origen & $\begin{array}{l}\text { Deformación } \\
\text { Craneana }\end{array}$ & Fechas $(2 \text { sigma })^{2}$ \\
\hline $\mathrm{CH} 1.2$ & Femenino & $30-40$ & Costa & -- & $\begin{array}{l}134-356 \mathrm{cal} \mathrm{DC}[0.97214] \\
366-380 \mathrm{cal} \text { DC }[0.02786]\end{array}$ \\
\hline $\mathrm{CH} 2.1$ & Femenino & $30-40$ & Costa & -- & $342-540 \mathrm{cal}$ DC [1] \\
\hline $\mathrm{CH} 2.5$ & Masculino & $30-40$ & Interior & $\begin{array}{c}\text { Tabular erecto (leve a } \\
\text { moderado) }\end{array}$ & $\begin{array}{l}688-754 \mathrm{cal} \mathrm{DC}[0.253042] \\
756-890 \mathrm{cal} \mathrm{DC}[0.746958]\end{array}$ \\
\hline $\mathrm{CH}_{3.7}$ & Indeterminado & 4-6 Años & Costa & $\begin{array}{l}\text { Tabular oblicuo } \\
\text { (fuerte) }\end{array}$ & $\begin{array}{c}140-156 \mathrm{cal} \mathrm{DC}[0.020454] \\
167-195 \mathrm{cal} \text { DC }[0.038343] \\
209-400 \mathrm{cal} \mathrm{DC}[0.941203]\end{array}$ \\
\hline $\mathrm{CH}_{3} .8$ & Masculino & $30-40$ & Costa & -- & $\begin{array}{l}1302-1364 \mathrm{cal} \text { DC }[0.57664] \\
1376-1421 \mathrm{cal} \text { DC }[0.42336]\end{array}$ \\
\hline $\mathrm{CH}_{7.5}$ & Indeterminado & Adulto & Interior & Ausencia & -- \\
\hline $\mathrm{CH} 9.1$ & Indeterminado & $<6$ Meses & -- & Ausencia & $\begin{array}{l}1449-1522 \mathrm{cal} \mathrm{DC}[0.543322] \\
1536-1626 \mathrm{cal} \text { DC }[0.456678]\end{array}$ \\
\hline $\mathrm{CH}_{9.6}$ & Masculino & $20-30$ & -- & -- & $\begin{array}{c}43 \mathrm{cal} \mathrm{AC}-139 \mathrm{cal} \text { DC [0.981657] } \\
157-169 \mathrm{cal} \text { DC [0.009016] } \\
197-208 \mathrm{cal} \mathrm{DC}[0.009327]\end{array}$ \\
\hline $\mathrm{CH} 18.1$ & Masculino & $20-40$ & Interior & -- & $\begin{array}{l}821 \mathrm{cal}-537 \mathrm{cal} \mathrm{AC}[0.994439] \\
530 \mathrm{cal}-524 \mathrm{cal} \mathrm{AC}[0.005561]\end{array}$ \\
\hline
\end{tabular}

Tabla 2. Resumen de información bioarqueológica y fechados directos de los individuos excavados en el área de Calate.

1 Todas las fechas se obtuvieron del University of Arizona Accelerator Mass Spectroscopy Laboratory. La edades radiocarbónicas fueron calibradas en Calib 6.0 (McCormac et al. 2004; Stuiver et al. 2005) usando la curva SHCALo4.

la identificación de estas lesiones nos permitirá distinguir si algunos de estos individuos fueron víctimas de ataques. Por último, se examinaron los restos en busca de traumas peri-mortem o heridas que ocurren cercanas al momento de la muerte, que, aunque difíciles de identificar, cuando están presentes proporcionan la evidencia más directa de conflictos letales, que en este caso hablarían de ataques en la ruta.

Finalmente, se consideró para cada caso su contexto arqueológico, lo que incluyó la ubicación de la tumba, el período en que vivió cada individuo y la manera en que fue enterrado. La ubicación de las tumbas se consideró en relación a las rutas y a otras evidencias arqueológicas, mientras que la adscripción temporal de cada viajero se realizó mediante el fechado radiocarbónico de ocho de los nueve individuos a partir de muestras de restos óseos. En cuanto a la manera en que fueron enterrados, se tomó en cuenta el estilo de la construcción de cada tumba, las que variaron desde algunas muy expeditivas hasta otras que requirieron gran inversión de trabajo, considerándo- se además la variedad y abundancia de las ofrendas en cada caso.

Es la combinación de todos estos datos la que nos permitirá acercarnos a la vida de estas personas que murieron viajando por el desierto de Atacama, partiendo de la perspectiva del individuo para luego proponer una visión más global de la experiencia de la muerte y tratamiento de los muertos a lo largo de las rutas.

\section{* Contextos mortuorios de Calate}

Comenzaremos con una breve discusión sobre las tumbas en relación a su ubicación y aspectos formales, para luego seguir con una descripción más detallada de los contextos mortuorios propiamente tales. Un primer punto a resaltar es que los nueve entierros recuperados en el sector de Calate estaban asociados con recintos habitacionales $y / 0$ estructuras ceremoniales a nivel de sitio, aunque con una tendencia a la sectorización del 
espacio mortuorio que, en siete casos, estaba diferenciado de las otras estructuras y alejado del eje de tránsito. Solo dos tumbas ( $\mathrm{CH}_{2} .5$ y $\left.\mathrm{CH}_{3} .8\right)$ se dispusieron directamente sobre áreas habitacionales y en cercanía a los senderos, una de las cuales ( $\mathrm{CH} 2.5)$ incluso reocupó el interior de una estructura previamente usada como campamento de descanso.

Otro aspecto significativo es el tipo de construcción mortuoria, distinguiéndose dos extremos formales y una situación intermedia. En primer lugar identificamos dos casos de estructuras aéreas con entierros visibles, en que los cuerpos fueron dispuestos sobre la superficie y luego cubiertos con una estructura simple de piedras, dejando parte del cuerpo expuesto (tumbas $\mathrm{CH}_{2} .1$ y CH2.5); ambos casos corresponden a entierros secundarios, por lo que su expeditividad constructiva parece relacionarse justamente con la remoción y/o traslado post-mortem que acusan. Esta modalidad se vincula con entierros del período Formativo Tardío y el período Medio. Una situación intermedia se observó en dos tumbas $\left(\mathrm{CH}_{3} .8\right.$ y $\mathrm{CH} 18.1$ ), correspondientes a entierros superficiales, pero donde se invirtió una mayor energía que generó una estructura semi monticular (de plantas lineal y oval) de baja altura, aunque lo suficientemente cubierta para no mostrar restos mortuorios expuestos en superficie. Esta práctica fue fechada tanto en el período Formativo Temprano como en el período Intermedio Tardío, lo que la vincularía más con situaciones particulares que tuvieron que resolver los viajeros, que con prácticas de temporalidad específica. En el otro extremo se encuentran los entierros en fosas circulares, las que ostentan la mayor inversión de trabajo, variedad contextual y, por lo general, la mejor conservación (tumbas CH1.2, $\mathrm{CH}_{3} \mathrm{~N} .7$, $\mathrm{CH}_{7.5}$, $\mathrm{CH}_{9} .1$ y $\mathrm{CH}_{9}$.6). En superficie se encuentran demarcadas por amontonamientos simples de piedras rellenados con sedimento, otorgándoles un aspecto monticular. Ésta fue una práctica mortuoria que se desarrolló en distintos períodos, involucrando el período Formativo Medio, el período Intermedio Tardío y el período Inka/Colonial Temprano.

De acuerdo a la relación con las conexiones viales (Figura 1), podemos establecer que la tumba del sitio $\mathrm{CH}_{1} 8$ se asociaba con senderos que comunicaban Quillagua con la costa. El resto de los entierros se ubicaron en sectores que muestran un alto grado de superposiciones, desvíos y ramales de senderos donde las diversas vías procedentes de Atacama, Tarapacá y la costa confluyen, por lo que no pudieron ser asignados a conexiones más particulares.

En cuanto a los contextos mortuorios excavados, los análisis bioarqueológicos revelaron una importante variedad de individuos y ajuares, contextos que describiremos a continuación en orden cronológico (Tabla 2).

\section{Período Formativo}

Se identificó un único entierro perteneciente al período Formativo Temprano (CH18.1), indicando el uso temprano de esta red vial entre la costa y el interior. El cuerpo estaba dispuesto directamente sobre la superficie y cubierto con un pequeño montículo suboval de piedras y sedimento, quedando parcialmente expuesto después de algún tiempo. Este es un patrón que se repite a lo largo del tiempo y es indicativo de los casos en que un individuo es enterrado de manera muy expeditiva y con baja inversión mortuoria, lo que alude a un contingente mínimo, quizás un único acompañante, que lo entierra sin la posibilidad de replicar las prácticas mortuorias locales. Los huesos estaban muy meteorizados, pero a pesar de que no se pudo analizar el esqueleto para identificar trauma o modificación craneana, se determinó que la tumba contenía los restos de un adulto masculino entre 20 y 40 años de edad, quien evidenciaba una leve osteoartritis en las rodillas. El entierro contenía escaso material cultural asociado y, aunque éste incluía restos de pescado y otros productos marinos, al parecer se trataría de un individuo vinculado con el interior. ${ }^{5}$

Del período Formativo Medio, se identificó también un único entierro ( $\left.\mathrm{CH}_{9} .6\right)$, el cual fue substancialmente intervenido post-mortem. Bajo un túmulo circular de baja altura y cubierto con piedras dispersas se pudo observar una fosa poco profunda que contenía la pelvis y los miembros inferiores de un hombre de 20 a 30 años, momificados naturalmente. Cabe destacar que el resto del cuerpo estaba ausente, aunque la forma y tamaño de la fosa parecen indicar que sí estuvo enterrado en algún

\footnotetext{
5 Esto de acuerdo a recientes análisis de paleodieta basados en isótopos estables de carbono y nitrógeno, que sugieren una dieta compuesta mayoritariamente por recursos del interior para los últimos 10-30 años de la vida del individuo (Pestle et al. Ms).
} 


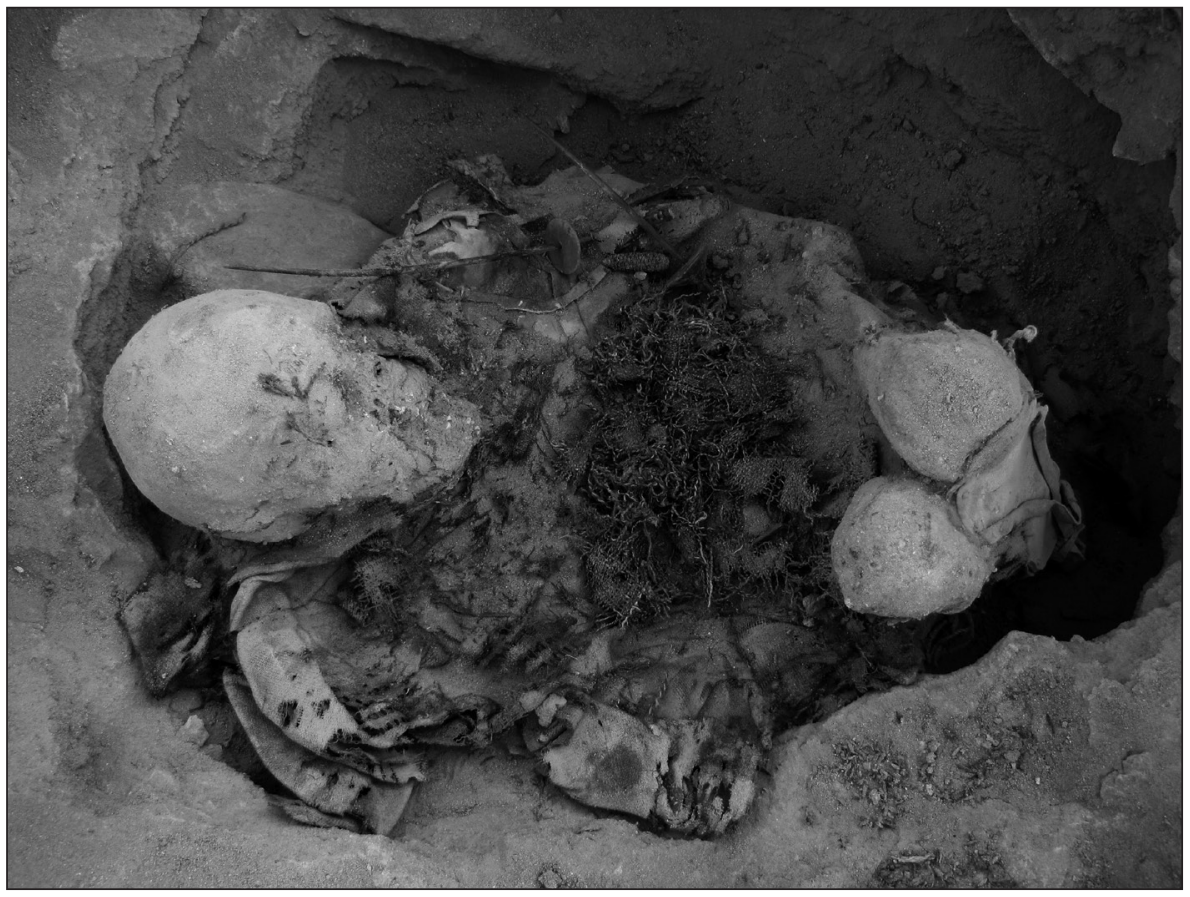

Figura 2. Detalle del entierro CH1.2 durante la excavación, donde se observa la fosa en que fue depositado el individuo y algunos de los elementos que componían su ajuar.

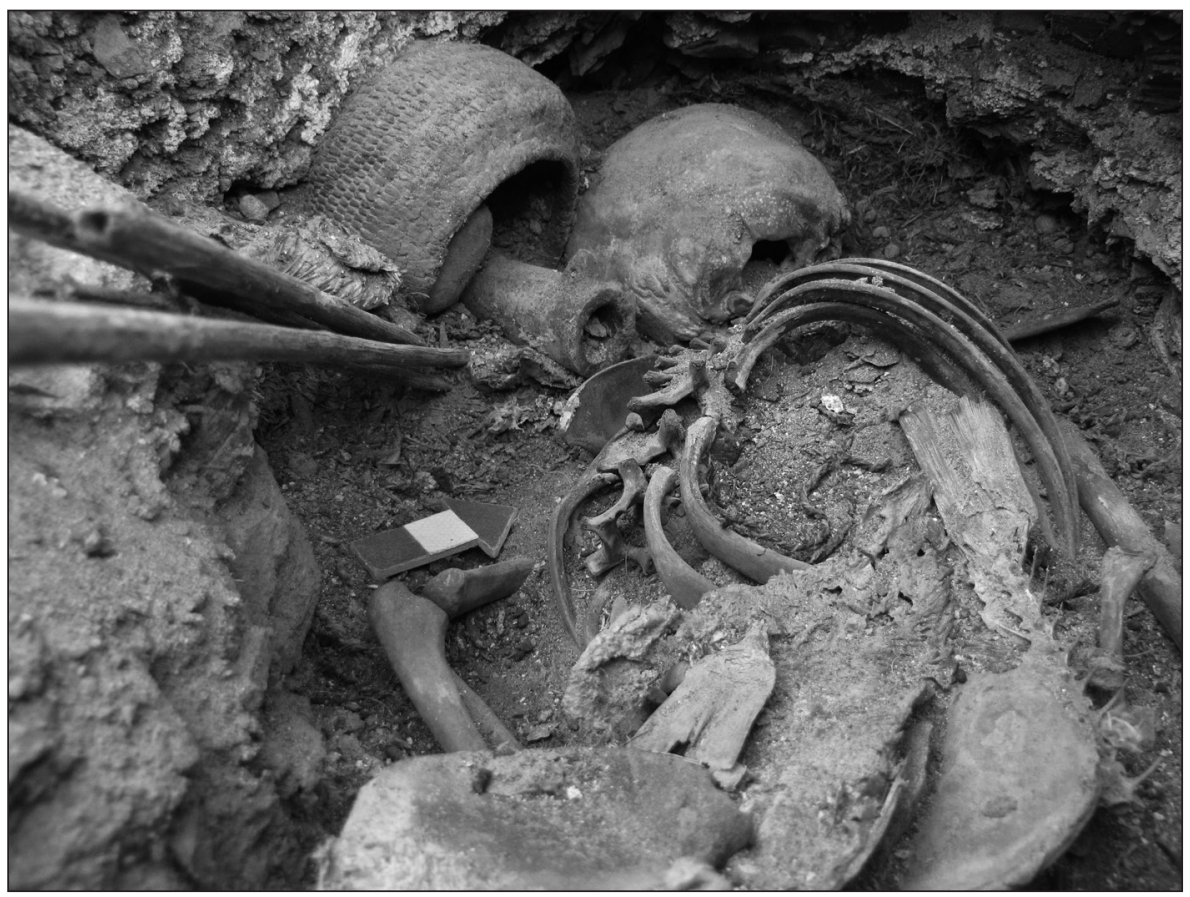

Figura 3. Detalle del contexto mortuorio $\mathrm{CH}_{3} \mathrm{~N} .7$ durante la excavación; junto al esqueleto del niño se observan algunas de las ofrendas que lo acompañaban, incluyendo restos de pescado. 
momento. El análisis de los escasos restos óseos presentes no evidenció patologías ni traumas. Tampoco se observaron ofrendas.

Dos individuos pertenecientes al período Formativo Tardío ( $\mathrm{CH}_{1.2}$ y $\mathrm{CH}_{3} \mathrm{~N} .7$ ) fueron enterrados en fosas que requirieron mayor inversión constructiva, pese a lo cual son bastante diferentes entre sí. CH1.2 es la tumba de una mujer de 30 a 40 años de edad, tratándose de un entierro primario en una fosa de casi un metro de profundidad. El cuerpo presenta un alto grado de momificación natural, pero con una remoción post-mortem del cráneo y otros elementos del tórax; consistente con esto, en la excavación se pudo reconocer una intervención posterior que disturbó parcialmente el entierro. Las piernas se encontraban atadas con cordeles, probablemente como parte del procesamiento del cuerpo para el entierro. El análisis de los restos óseos que pudieron ser observados no evidenció traumas o patologías. Destacan las numerosas ofrendas que acompañaban a esta mujer, las cuales incluían una bolsa anillada en fibra vegetal que contenía conchas de choro (Choromytilus chorus), un embarrilado de fibras vegetales, una vestimenta de cuero de ave marina que estaba adosada al cuerpo, un cobertor púbico de fibra vegetal compuesto de varios cordeles gruesos, fragmentos de tejido y cerámica, una aguja de hueso pulido, lascas líticas, y un cuenco abierto de cestería fina (Figura 2). El conjunto del material cultural sugiere el origen costero del individuo. Se debe notar que tres fragmentos de cerámica pertenecían a un cántaro del tipo Turi Rojo Alisado del período Intermedio Tardío, algo que puede sugerir el momento de intervención post-mortem de la tumba.

La tumba $\mathrm{CH}_{3} \mathrm{~N} .7$ fue encontrada aislada de la ruta, a los pies de cerros bajos (Figura 3). Se trata de un entierro primario en fosa, con gran inversión de trabajo y abundantes ofrendas acompañando los restos de un niño de 4 a 6 años de edad, con una deformación tabular oblicua bien marcada. No hay señales de patologías en los restos óseos. Del interior de la fosa se recuperó un cuenco de cestería que contenía un pequeño vasito cónico de cerámica y un fragmento distal de pipa de cerámica asociada con el Noroeste Argentino; se ofrendaron también dos vasijas completas, ocho astiles embarrilados con restos de plumas en su parte distal, y los restos de una vestimenta de cuero de ave marina, la cual frecuentemente se asocia con individuos costeros. Se identificó además un coxal adulto asociado a este entierro, que puede ser evidencia de una intervención secundaria.

Finalmente, la tumba $\mathrm{CH} 2.1$ fue fechada con un rango de calibración que abarca desde los finales del período Formativo Tardío hasta los inicios del Período Medio, aunque culturalmente se vincularía con el Formativo Tardío. ${ }^{6}$ Corresponde a un entierro superficial secundario y sin mayor inversión de trabajo. Los restos están bastante meteorizados y el cuerpo parcialmente desarticulado post-mortem, indicando que estuvo parcialmente expuesto. Contenía el esqueleto de una mujer de 30 a 40 años de edad que fue cubierta con un amontonamiento de piedras grandes. No se notó evidencia de traumas ni de otras patologías y la destrucción del cráneo no permitió el análisis de modificación craneana. Como ajuar, poseía solamente un tipo de vestimenta de cuero de ave marina que sugiere un origen costero.

\section{Período Medio}

Una sola tumba ( $\mathrm{CH} 2.5)$ fue asignada directamente al período Medio. Al igual que el caso anterior, corresponde a un entierro superficial y secundario, sin mayor inversión de trabajo. El cuerpo se encontraba bastante meteorizado y parcialmente desarticulado post-mortem, indicando que parte de él estuvo también expuesto por un tiempo. Se trata de un hombre de 30 a 40 años de edad, con deformación craneana leve de forma tabular erecta (estilo asociado al interior; Torres-Rouff 2007) y un desgaste dental severo (documentado también para las poblaciones del interior; Hubbe et al. 2012). Al parecer, la tumba correspondería a la reutilización de un espacio de carácter habitacional, donde el cuerpo fue depositado sobre un textil y luego simplemente cubierto, sin excavarse una fosa. En contraste con la mujer enterrada en el mismo sitio, este individuo estaba acompañado

\footnotetext{
6 Se debe precisar que en todo el artículo las referencias al período Medio se ocupan operacionalmente para dar cuenta de la secuencia temporal regional (ca. 500-900 DC) y no alude en ningún caso a las relaciones o evidencias de la influencia directa del Estado tiwanakota. Dado que los contextos viales son espacios esencialmente multiculturales, incluso con presencia de alfarería tiwanakota en algunas vías del desierto, resultaría totalmente vago y poco operacional diferenciar la tradicional distinción entre nodos con o sin presencia del período Medio para el caso de los espacios de movilidad internodal.
} 
por una gran variedad y abundancia de ofrendas comestibles, incluyendo pescado y algarrobo.

\section{Períodos Tardíos}

Dos de las tumbas de Calate pertenecen al período Intermedio Tardío ( $\mathrm{CH}_{3} .8$ y CH7.5). El entierro $\mathrm{CH}_{3} .8$ corresponde a un hombre de 30 a 40 años de edad y sin evidencia de patologías. Su disposición sobre la vía y caído de manera extendida sobre su frente parece indicar que tuvo una muerte repentina; fue cubierto por un amontonamiento bajo de piedras, de tendencia lineal. La destrucción de su cráneo post-mortem no permitió determinar si presentaba deformación craneana. El cuerpo se encontró bastante meteorizado en su lado posterior, acompañado por una gran variedad de comestibles (maíz, pescado, algarrobo y chañar), además de fragmentos de cerámica tardíos (Figura 4). Destacase una línea de pigmento rojo pintada en su miembro superior izquierdo, mientras que una de las piedras que cubría el cuerpo tenía restos de pigmento del mismo color (Figura 5).

La tumba $\mathrm{CH}_{7.5}$ corresponde a un entierro primario en fosa, con una enorme inversión de trabajo y abundantes ofrendas. Este adulto de sexo indeterminado se encuentra casi completamente momificado naturalmente. El individuo fue enterrado sentado y apoyado sobre una piedra grande. No muestra evidencia de modificación craneana y su alto grado de preservación no permitió el examen de traumas y patologías a partir de sus huesos. Se pudieron reconocer varios textiles diferentes, ya que al parecer el cuerpo fue depositado completamente enfardado, y también se observaron gruesos cordeles blancos de cuatro hebras agarrados en grandes nudos tras la espalda, los que probablemente formaron parte de un faldellín. El individuo fue enterrado vistiendo dos sandalias de cuero junto a una tercera sandalia depositada a modo de ofrenda sobre su hombro izquierdo; lo acompañaban también dos husos completos de madera, con sus palos y torteras de forma cónica y los restos de una bolsita de fino textil blanco, la que contenía un marlo de maíz y algunas vainas de algarrobo completas (Figura 6). Todo esto lo vincula con las poblaciones del interior.

La última tumba ( $\mathrm{CH}_{9.1}$ ) pertenece a los últimos momentos del período Tardío, entre el período Inka y principios de la era Colonial. Este individuo fue enterrado en una fosa y cubierto con una manta de cuero de ave marina. Corresponde a un neonato de menos de seis meses de edad, cuyo esqueleto se conservó de manera excelente. Como esperaríamos, el cuerpo no muestra señales de violencia o patologías. Tampoco presenta modificaciones en la forma del cráneo. Junto con el fardo, se encontraron numerosas ofrendas: cerámica monocroma negra (al parecer, un vasito), malla de red, carpos de algarrobo, un marlo de maíz, textilería, cordelería, y restos de pescado. Se debe notar que, semejante al entierro tardío de $\mathrm{CH}_{3} .8$, cerca de la tumba de $\mathrm{CH} 9.1$ se encontraron dos piedras con pigmento rojo, posiblemente relacionadas a rituales que formaron parte del entierro.

\section{* Viajeros en otras rutas del área CIRCUMPUNEÑA Y VALLES OCCIDENTALES}

Estos individuos de Calate no son los únicos cuerpos de viajeros que han sido documentados en el árido espacio del norte de Chile. Además de breves menciones de tumbas en pleno desierto (p. e. Bollaert 1860; Núñez 1976; Briones y Castellón 2005), se han publicado investigaciones que documentan otros viajeros prehispánicos en el área circumpuneña y Valles Occidentales (Tabla 3, ver Figura 7), donde se relatan dos enterramientos en Cerro Mono, en la Región de Tarapacá (Briones et al. 2005); un viajero muerto en el área de El Toco (Cases et al. 2008; Pimentel et al. 2011; Knudson et al. 2012) y los restos de dos individuos cerca del río Quepiaco, asociados a un paso transcordillerano (Barón 1999). ${ }^{7}$ Estos individuos reafirman algunos de los elementos que hemos documentado en las personas enterradas en Calate.

En el caso de Cerro Mono, los dos entierros se encuentran asociados a geoglifos (Briones et al. 2005: 209). El primero (tumba 1) se trata de un niño de 10 a 12 años cuyo contexto se encontraba alterado. Este individuo juvenil estaba envuelto en cuero de ave marina y llevaba faldellín, ambos elementos asociados con un origen costero por los autores. Tenía el cráneo modificado de forma circular oblicua. Los autores obtuvieron una fe-

\footnotetext{
7 Excluimos aquí los trabajos sobre los "viajeros" de Pulacayo ya que investigaciones más recientes indican que el área tuvo una densa ocupación y no funcionó como nodo interregional (com. pers. Axel Nielsen 2012; Cruz 2009; Lechtman et al. 2010).
} 


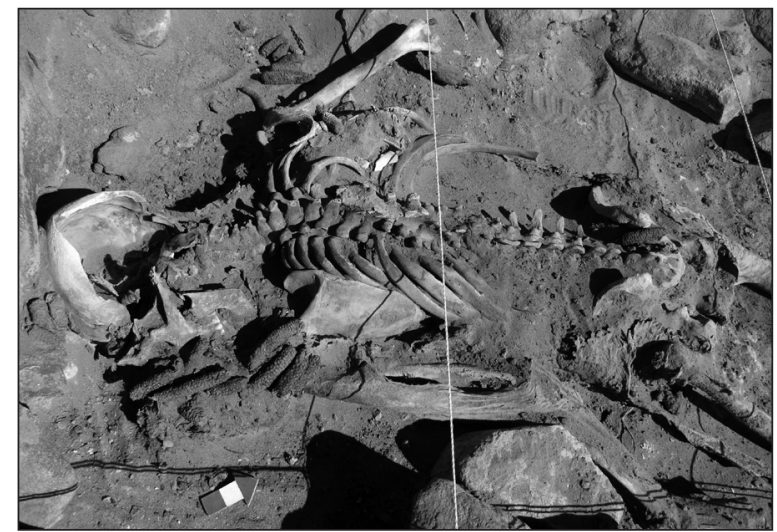

Figura 4. Detalle del entierro $\mathrm{CH}_{3} .8$ durante la excavación, destacando la posición del cuerpo, meteorización del cráneo y ofrendas vegetales.

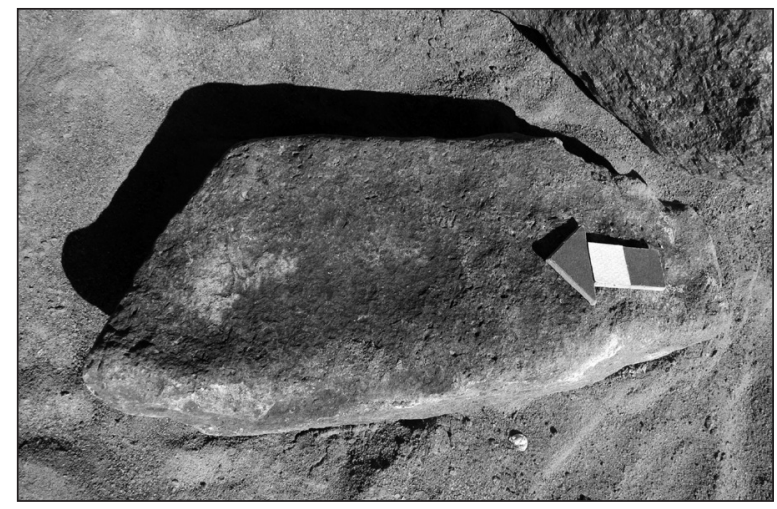

Figura 5. Piedra con restos de pigmento rojo que formaban parte de la tumba $\mathrm{CH}_{3} .8$.

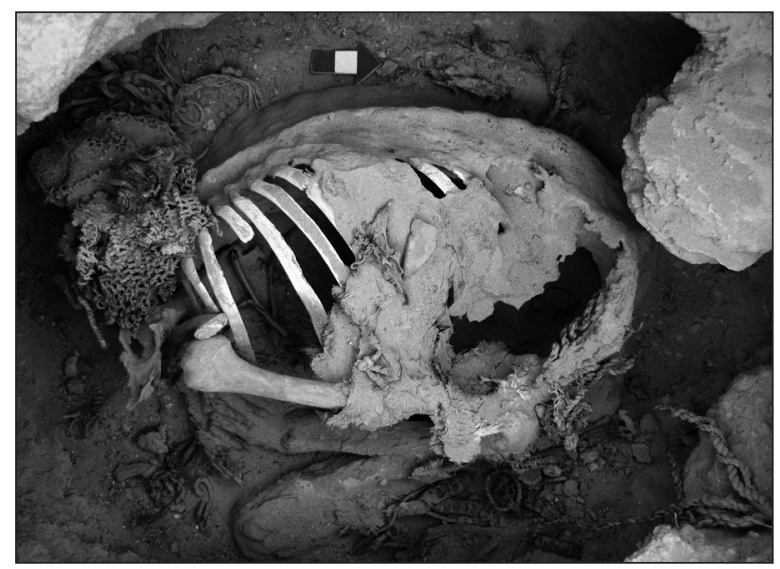

Figura 6. Detalle del entierro $\mathrm{CH}_{7.5}$ durante la excavación, donde se observa la fosa en que fue depositado el individuo y los elementos que componían su ajuar. 


\begin{tabular}{|c|c|c|c|c|}
\hline Individuo & Sexo & Edad & Período(Fecha) & Referencias \\
\hline Cerro Mono 1 & Indeterminado & 10-12 años & $\begin{array}{c}\text { Formativo Temprano } \\
\text { (Cal. 1.420-1.380 a.C.) }\end{array}$ & Briones et al. 2005 \\
\hline Cerro Mono 3 & Femenino & $25-30$ años & - & Briones et al. 2005 \\
\hline El Toco & Masculino & $28-35$ años & $\begin{array}{c}\text { Formativo Tardío (Cal. 40-230 d.C.; Cal. } \\
60-240 \text { d.C.) }\end{array}$ & $\begin{array}{r}\text { Cases et al. 2008; Pimentel et al. 2011; } \\
\text { Knudson et al. 2012) }\end{array}$ \\
\hline Paso de Quepiaco 1 & Masculino & $18-25$ años & -- & Barón 1999 \\
\hline Paso de Quepiaco 2 & Masculino & $18-25$ años & Barón 1999 \\
\hline
\end{tabular}

Tabla 3. Resumen de los restos de viajeros documentados en otros sitios del área.

cha radiocarbónica para esta tumba que la sitúa en el período Arcaico Tardío final o Formativo Temprano (3.110 $\pm 40 \mathrm{C} 14$ AP; Briones et al. 2005: 213), que resulta ser más temprana que los geoglifos a su alrededor. La tumba 3, por su parte, contenía los restos de una mujer de 25 a 30 años que estuvieron expuestos por un tiempo antes de ser cubiertos por piedras (Briones et al. 2005: 211). Los restos estaban muy destruidos y no proveyeron muchos detalles, pero los autores también sugieren un origen costero para esta mujer, aunque de fecha más tardía que la tumba 1.

El individuo encontrado en El Toco, en plena Depresión Intermedia (Cases et al. 2008; Pimentel et al. 2011; Knudson et al. 2012) fue sujeto a numerosos estudios, los cuales arrojaron un origen costero y fecha Formativa para este hombre que murió entre los 28 y 35 años de edad. La preservación de sus restos no permitió hacer análisis de modificación craneana, ya que el cráneo estaba fragmentado y sufrió deformación post-mortem. Los huesos disponibles no mostraron evidencias de heridas traumáticas. Estos tres individuos de diversas edades y géneros muertos en las tierras bajas del desierto absoluto apoyan nuestra idea de que la movilidad andina incluía a grupos familiares completos, con estrategias más diversas que las propuestas tradicionalmente.

Moviéndonos a tierras altas, en los alrededores del río Quepiaco, a 4.700 m.s.n.m. se recuperaron dos individuos que parecen haber muerto en el mismo momento. Aunque no se entregan muchos detalles sobre el contexto mortuorio, se tratan de jóvenes masculinos de 18 a 25 años de edad, uno de ellos con deformación tabular oblicua (Barón 1999). En contraste a muchos de los otros viajeros documentados, éstos nunca fueron enterrados o cubiertos, quedando simplemente depositados entre las piedras donde murieron, preservándose las vestimentas y el material cultural que portaban. Desafortunadamente, no se establece a qué época pertenecieron, aunque a partir del tipo de túnica que llevaban, corresponderían al período Intermedio Tardío (900-1450 DC).

Junto a los individuos de Calate, el conjunto de estos datos nos muestra que la muerte en tránsito no fue una situación inusual. Gracias a la notable preservación de los restos en el ambiente árido del norte de Chile, es posible estudiar los viajes precolombinos desde una perspectiva que considera a los viajeros mismos.

\section{Vida y muerte en las rutas}

Como acabamos de ver, Calate no es el único lugar que alberga restos de viajeros muertos en ruta; éstos se han documentado en otros lugares del norte de Chile y altiplano boliviano, y probablemente reflejan una realidad que formaba parte de los viajes de larga distancia realizados por estas poblaciones. En términos económicos, las rutas que atraviesan Calate conectan los abundantes recursos marinos de la costa y la desembocadura del río Loa con las zonas boscosas de Quillagua. Por otra parte, las rutas siguen desde la confluencia de Quebrada Amarga con el río Loa también hacia el norte, a Tarapacá. Estas conexiones nos hablan entonces de la anhelada complementariedad de recursos, las que en esencia sirven como importantes vías entre poblaciones diversas.

Llama la atención la relativamente alta cantidad de muertos en tránsito registrados en esta área tan acotada. Es 


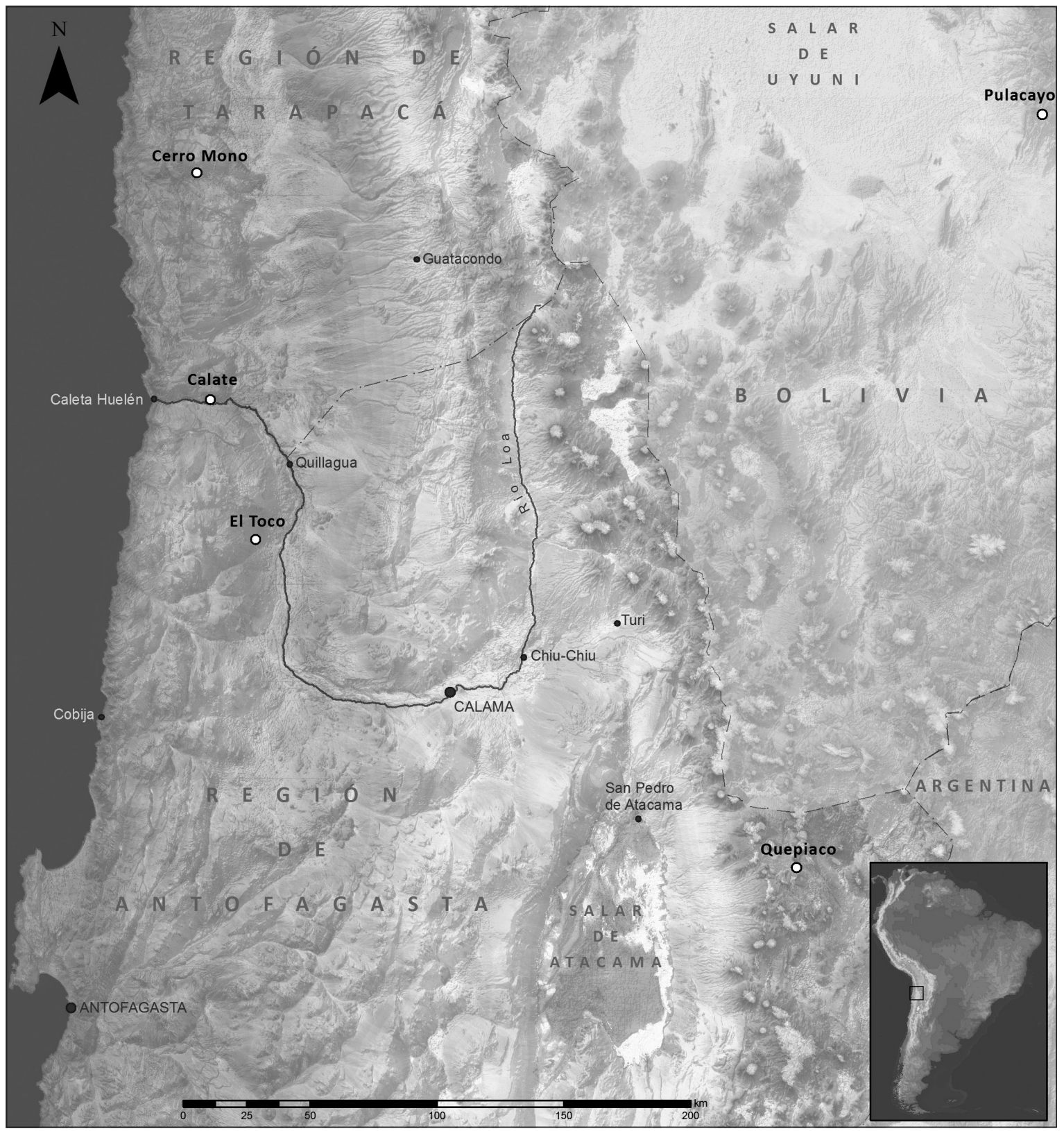

Figura 7. Mapa del norte de Chile y suroeste boliviano, indicando los sitios donde se han encontrado viajeros muertos en ruta mencionados en el texto.

posible que tal situación derive de que en esta región se hicieron la mayor cantidad de estudios sobre el tema, pero también cabe mencionar la ubicación geográfica de Calate, en pleno desierto y distante de los parches de recursos, al tratarse de un área cuyas condiciones ambientales son extremas, con altas temperaturas, fuertes vientos y una importante inaccesibilidad respecto al río que aquí corre al fondo de un profundo y escarpado cañón. No resulta difícil imaginar que estas condiciones hayan creado un ambiente desafiante para los viajeros, situación que perduró en el registro arqueológico bajo la forma de estas tumbas. En contraste, cabe destacar 
que otras áreas cruzadas por senderos, que muestran igualmente geoglifos, sitios habitacionales y diversidad de manifestaciones rituales, carecen de entierros. No hemos registrado contextos mortuorios en ninguna de las conexiones analizadas desde Quillagua hacia las tierras medias y altas (Loa Medio y salar de Atacama), lo que grafica la singularidad y notoriedad del caso de Calate (Pimentel 2011, 2012).

La densidad poblacional de las áreas conectadas por las rutas que cruzaban Calate sugiere la intensidad del tráfico entre el interior de Atacama, Tarapacá y la costa Pacífica. Los trabajos en la desembocadura del río Loa (Spahni 1967; Núñez 1971; Núñez et al. 1975; Zlatar 1983), documentan complejos sitios ya desde el Arcaico Tardío en adelante, los que incluyen aldeas y cientos de entierros, con algunos cementerios de gran magnitud. La documentación de los cementerios de Quillagua por su parte también ha sugerido una alta densidad poblacional (Gallardo et al. 1993; Agüero et al. 2006), asociada a una dieta compuesta principalmente por recursos marinos, a pesar de su distancia de la costa (Santana 2011; Pestle et al. Ms). Por otra parte, las fechas obtenidas para los sitios $e$ individuos de Calate proveen evidencias de la reutilización de estos espacios de tránsito por diversas poblaciones a lo largo del tiempo.

Calate entonces se ubica en un espacio estratégico pero altamente desafiante, que conectó densas poblaciones especializadas en la explotación de recursos diferenciados y complementarios, configurándose como un área transitada con gran regularidad y frecuencia. Estos aspectos en conjunto redundaron en evidencias a nivel del individuo, haciendo de Calate un espacio particularmente apropiado en el estudio de los viajes prehispánicos.

Una visión general de los datos bioarqueológicos e osteobiográficos muestra que los individuos varían mucho. Los datos demográficos muestran desde pequeños niños a adultos de ambos sexos y de un amplio rango de edad. La evidencia de modificación craneana entre estas personas muestra la misma variabilidad: dos de los cuatro individuos que tienen el cráneo en estado adecuado para su estudio no muestran evidencia de deformación, mientras que los otros dos tienen modificaciones de formas tabular erecta $\left(\mathrm{CH}_{2} .5\right)$ y tabular oblicua $\left(\mathrm{CH}_{3} .7\right)$. Mientras la modificación craneana tiene fuertes vínculos con los lugares de origen y prácticas familiares de las personas, la deformación tabular erecta del individuo $\mathrm{CH} 2.5$ apoya la interpretación de su pertenencia a grupos del interior basada en el material cultural, siendo este estilo de deformación craneana el más común en los oasis del interior del desierto de Atacama (Torres-Rouff 2007).

No se observaron evidencias de violencia ni de ataques que hubieran causado la muerte de algunos de estos individuos en las rutas de Calate. Esto no implica que todos hayan muerto pacíficamente, ya que la ausencia de violencia no se pudo precisar con total certeza debido al estado de preservación de los cuerpos. La posibilidad de que existiesen situaciones violentas a lo largo de las rutas no resultaría sorprendente. De hecho, el contexto del individuo $\mathrm{CH}_{3} .8$ sugiere la posibilidad de violencia a pesar de que los huesos visibles no la muestran. Fue encontrado extendido sobre su frente, como si hubiera caído en el momento de su muerte. La meteorización de su esqueleto sugiere que quedó expuesto por un período de tiempo después de morir. Podemos imaginar que quizás cayó en una emboscada o fue atacado de alguna manera que obligó a huir a sus compañeros de viaje. Tal vez solo tuvieron breves momentos para cubrirlo con arena, la que desapareció con el tiempo, dejando su cuerpo expuesto. Lo que sí sabemos es que el desgaste y la exposición del cuerpo sugieren que no fue hasta mucho más tarde que otras personas, que recorrían las mismas rutas, pudieron tomarse el tiempo para proporcionarle los ritos funerarios apropiados: su cuerpo fue entonces cubierto con piedras, evitando la destrucción de su cadáver. Es posible que haya sido en este momento cuando se pintó con pigmento rojo una de las piedras que lo cubría y también se haya dibujado la línea sobre su brazo izquierdo. El acto de enterrar cuerpos que ya han estado expuestos por un tiempo es observado también en otros entierros de Calate y de otras áreas, sugiriendo la reocupación y frecuencia del tráfico por estas rutas. Se debe mencionar que muchos de los contextos mortuorios en Calate demuestran la importancia de enterrar a los difuntos, aun si las muertes ocurrieron en lugares foráneos.

Considerando los modelos de movimiento e interacción, varios de los individuos excavados en Calate encajan en las características clásicas del modelo caravanero: al menos cuatro de los siete adultos identificados correspondieron a varones y varios se encontraron acompañados 


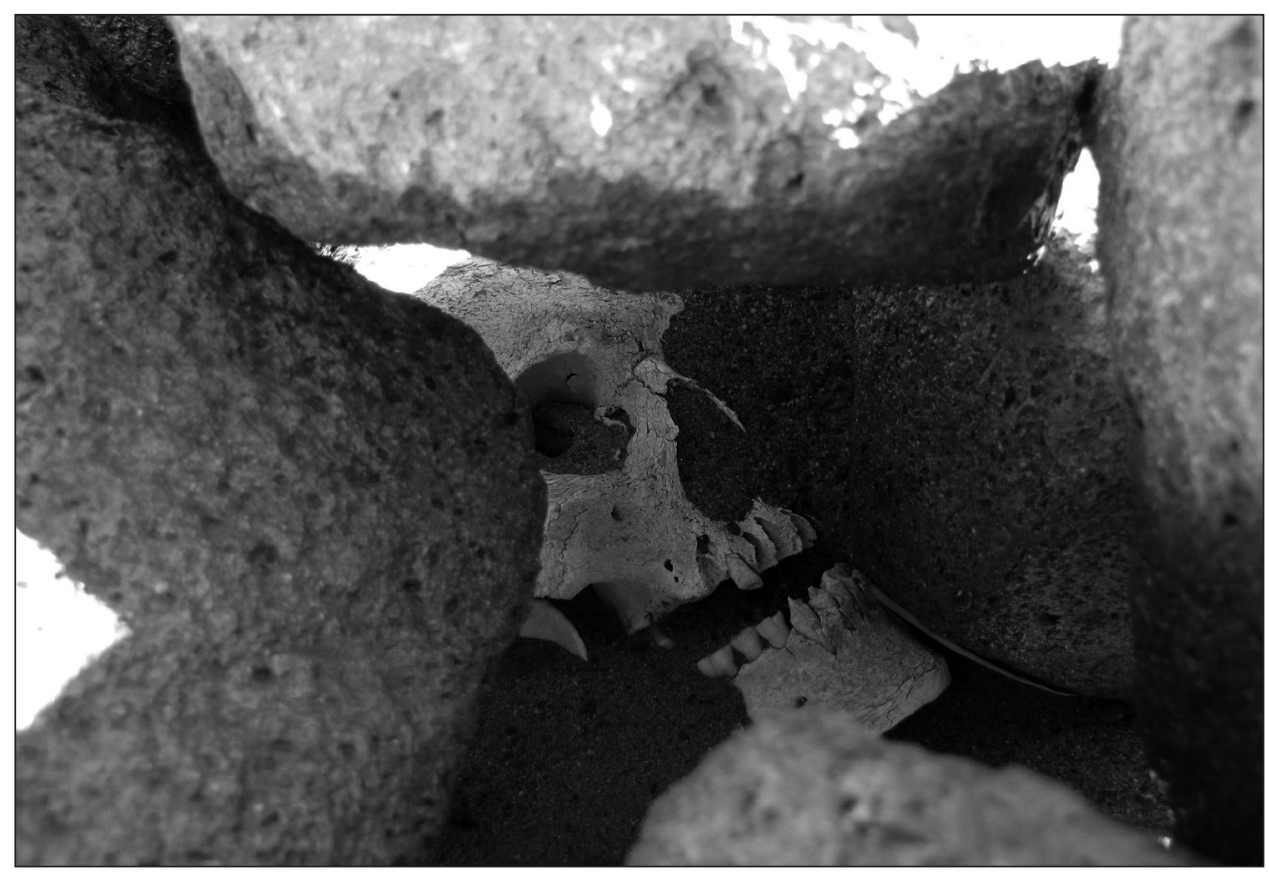

Figura 8. Detalle del cráneo en el entierro $\mathrm{CH}_{2} .5$, visible bajo las piedras que formaban su tumba.

de material cultural propio de tierras altas. Por ejemplo, el individuo $\mathrm{CH}_{2} .5$ es un adulto masculino enterrado bajo un amontonamiento de piedras (Figura 8). Su deformación craneana tabular erecta lo asocia con las poblaciones agrícolas del interior. Él no fue sepultado con muchos bienes, acompañado solo por textiles y una concentración de restos de camélido y alimentos. Su tumba fue ubicada en un espacio de carácter habitacional, mostrando la reutilización del mismo espacio habitacional de viajeros y reafirmando esta idea de viajes recurrentes de individuos.

Por otra parte, las evidencias de mujeres y niños que murieron a lo largo de estas rutas nos indican que esta imagen del tránsito como una labor exclusiva de hombres dirigiendo caravanas de llamas es incompleta, sugiriendo una mayor variabilidad en las estrategias de movilidad prehispánicas. El individuo enterrado en $\mathrm{CH} 1.2$ es una mujer adulta sepultada con una gran inversión de trabajo. Se excavó una fosa profunda en el caliche donde se construyó una pequeña estructura circular, dentro de la cual se depositó el cuerpo. No se encontró el cráneo ni parte del hombro izquierdo, posiblemente debido a una alteración posterior. Dentro de los numerosos objetos que constituyeron su ofrenda mortuoria, destaca como elemento característico de las poblaciones costeras: una bolsa de malla de red que contenía conchas de choro (Figura 2). La observación de los bienes materiales que acompañaron a esta viajera en su muerte sugiere que ella pertenecía más bien a poblaciones costeras.

Es sin embargo la presencia de niños pequeños - nuestro tercer grupo demográfico- la que difícilmente puede ser encajada en el modelo caravanero clásico. Se ha planteado recientemente que existió una modalidad costera de movilidad transversal, centrada en el movimiento logístico para la obtención de recursos del interior (Pimentel et al. 2010a, 2011a). Creemos posible interpretar la presencia de niños como parte de una movilidad costera, aunque estas nuevas evidencias agregan elementos aún inexplorados a la comprensión de los movimientos post arcaicos en el desierto de Atacama. Por ejemplo, es obvio que los niños pequeños no podrían haber completado estos trayectos solos y el tratamiento elaborado proporcionado al entierro del individuo $\mathrm{CH}_{3} \mathrm{~N} .7$ lo confirma. Este infante murió entre los cuatro y seis años de edad. Su cabeza había sido modificada de una manera que la amplió y creó una larga pendiente hacia atrás (tabular 
oblicua). Como mencionamos anteriormente, esta forma de deformación no está exclusivamente ligada a un grupo particular. Sus restos no mostraron evidencias de patologías o de enfermedades crónicas que pudiesen haber afectado su viaje, ni tampoco fueron marcados con signos de violencia. Sin embargo, el duelo de los que viajaban con este niño fue expresado en su tumba, indicando un esfuerzo considerable en su construcción, ya que se excavó una profunda fosa en el duro caliche donde se colocó el pequeño cuerpo envuelto en múltiples tejidos. Una serie de objetos, algunos presumiblemente de valor tanto económico como sentimental, fueron colocados alrededor de su cuerpo (ver Figura 3). Esto incluía vasijas de cerámica completas de tradición tarapaqueña, comida, astiles y un cesto que contenía un fragmento distal de pipa de cerámica acodada con patas, con un modelado zoomorfo propio del patrón San Francisco del Noroeste Argentino, que delata amplias relaciones de intercambio y tráfico a larga distancia. Cabe mencionar que el hornillo de la pipa se encontraba relleno con el mismo sedimento de la fosa, sin mostrar evidencias de haber estado en uso al momento del entierro; por el contrario, muestra señales de pulimento por manipulación y el sector de la fractura también se encuentra desgastado, por lo que creemos que se portaba como un objeto de carácter más bien simbólico, y no como un artefacto fumatorio propiamente tal. Este contexto mortuorio no solo nos relata aspectos sobre este niño en particular, sino que nos muestra un patrón que se desencaja tanto de la clásica modalidad caravanera de las tierras altas, como de la idea de un movimiento costero puramente logístico.

De esta manera, tanto la presencia de mujeres y niños viajeros, como también de gente de la costa, hacen alusión a una manera de movilidad diferente de la caravanera. Esto nos obliga a reconsiderar la visión de los movimientos costeros como meramente logísticos, llevándonos a considerar la posibilidad de una movilidad residencial. Los detalles aquí presentados sobre las muertes y entierros de estos viajeros nos permiten vislumbrar sus experiencias, las que nos hablan de dos formas considerablemente diferentes de movilidad, que convivieron a lo largo del tiempo y del espacio en estas rutas transdesérticas. De los nueve individuos excavados, tres parecen corresponder a viajeros caravaneros pertenecientes a grupos del interior ( $\mathrm{CH}_{2} .5, \mathrm{CH}_{1} 8.1$ y $\mathrm{CH}_{7}$.5), dos de los cuales son hombres adultos y el tercero de sexo indeterminado. Se trata de un registro bastante homogéneo que coincide con el modelo caravanero, donde hombres y niños varones funcionan como agentes especializados de la comunidad. Los dos individuos de tierras altas (Quepiaco) también corresponden a hombres, cuyo entierro es consistente con el modelo caravanero y calza muy bien con la clásica imagen etnográfica del grupo caravanero compuesto por hombres e hijos del grupo nuclear.

Pero más allá de la existencia de estos movimientos caravaneros del interior, nuestros datos apoyan la idea de una movilidad transversal propiamente costera propuesta por Pimentel y colaboradores (2011) aunque lo que vemos en Calate no es evidencia de un movimiento costero solamente logístico. Los individuos cuyo origen probable se encuentra en la costa ( $\left.\mathrm{CH}_{1} .2, \mathrm{CH}_{2} .1, \mathrm{CH}_{3} \mathrm{~N} .7, y \mathrm{CH}_{3} .8\right)$ presentan la mayor diversidad etaria y sexual, incluyendo hombres, mujeres y niños. Estos datos aluden a una movilidad residencial, probablemente estacional a fines de la época estival y enfocada en la recolección de algarrobo en los oasis; lo cual respondería a un movimiento transdesértico de la costa a los oasis y valles bajos, que habría comprometido a toda la unidad doméstica, sin el apoyo de animales de carga.

Es así que este trabajo viene a ampliar el modelo planteado para el sector de El Toco (Cases et al. 2008; Pimentel et al. 2011; Knudson et al. 2012), mostrándonos que existió una modalidad de movilidad costera que no consistió solamente en una estrategia logística llevada a cabo por hombres adultos, sino que posiblemente estuvo en funcionamiento una estrategia residencial que involucró a todo el grupo familiar.

\section{$*$ Conclusiones}

Los contextos mortuorios recuperados a lo largo de las rutas que se encuentran entre la confluencia de Quebrada Amarga y la desembocadura del río Loa nos ilustran un panorama más diverso que aquel descrito para la movilidad post-arcaica. Los restos de estos individuos sirven como un lente a través del cual mirar estos viajes por el desierto absoluto. Empleando un enfoque osteobiográfico, podemos utilizar las historias de sus vidas para abordar las preguntas que hemos planteado anteriormente: ¿quiénes eran los que realizaban los largos viajes transde- 
sérticos?, ¿era una actividad que recaía solo en determinadas sociedades, eran grupos especializados o era una actividad generalizada a todos los agentes y sociedades?

Logramos aquí, por primera vez, identificar una nueva forma de movilidad para las poblaciones costeras sur andinas; ésta involucraba un movimiento residencial, posiblemente de carácter estacional, de poblaciones del litoral hacia el interior, en este caso desde caleta Huelén. De acuerdo a los contextos mortuorios de Cerro Mono (Briones et al. 2005), es posible retrotraer con toda seguridad este tipo de modalidad hasta aproximadamente el 1400 AC, a finales del período Arcaico Tardío e inicios del Formativo Temprano. Mientras los datos confirman una vez más la clásica imagen de caravanas llevadas principalmente por hombres, se expande a su vez el conocimiento sobre la movilidad transversal costera, implicando a todos los integrantes de las unidades familiares. Sugerimos aquí que, dada la identificación de niños y mujeres en estos elaborados contextos mortuorios emplazados en áreas de tránsito, es posible vislumbrar una movilidad residencial sostenida por las poblaciones del litoral.

De esta manera, junto con una movilidad propiamente caravanera característica de los oasis del interior, se constata que las poblaciones costeras tuvieron sus propios procedimientos y objetivos diferenciados. Sin duda, resulta necesario seguir profundizando el estudio de estas prácticas con nuevos análisis y sistematizaciones, pero desde ya podemos afirmar que la movilidad entre el interior y la costa no estuvo restringida a viajeros caravaneros de tierras altas como los encargados exclusivos del tráfico, y que las poblaciones costeras de Atacama no poseían una movilidad longitudinal delimitada a lo largo del litoral solamente, ni tampoco restringida a una movilidad logística costa-interior, sino que involucraron una evidente mayor variabilidad de estrategias y múltiples sistemas de movilidad multidireccional, aspectos que recién comenzamos a develar.

Agradecimientos Este proyecto fue financiado por FONDECYT 1090762. Quisiéramos agradecer a Colorado College por su apoyo, a Lautaro Núñez, y a los equipos de excavación y gabinete: Lorena Arancibia, Benjamín Ballester, José Blanco, Magdalena García, Wilfredo Faúndes, Mark Hubbe, Tamara Pardo, Charles Rees, Sussy Rodríguez y Alexander San Francisco. Además, agradecemos al Instituto de Investigaciones Arqueológicas y Museo de San Pedro de Atacama y al Regimiento Topater de Calama por el apoyo logístico en terreno.

\section{* Referencias citadas}

AGÜERO, M. C., P. AYALA, M. URIBE, C. CARRASCO y B. CASES, 2006. El Período Formativo desde Quillagua. En Esferas de interacción prehistóricas y fronteras nacionales modernas, $\mathrm{H}$. Lechtman (Ed.), pp. 73-120. Institute of Andean Research, New York.

ARRIAZA, B. T., 1995. Beyond Death: The Chinchorro Mummies of Ancient Chile. Smithsonian Books, Washington D.C.

BARÓN, A. M., 1999. Arqueología y patrimonio cultural. Protección, hallazgos y conservación. Ed. Printas, Santiago.

BERENGUER, J., 2004. Caravanas, interacción y cambio en el desierto de Atacama. Sirawi y Museo Chileno de Arte Precolombino, Santiago.

BLOM, D. E., 2005. Embodying Borders: Human Body Modification and Diversity in Tiwanaku Society. Journal of Anthropological Archaeology 24 (1): 1-24.
BOLLAERT, W., 1860. Antiquarian, ethnological and other researches in New Granada, Equador, Peru and Chile, with observations on the PreIncarial, Incarial and other monuments of Peruvian Nations. Trübner \& Co., London.

BOUTIN, A. T., 2012. Crafting a Bioarchaeology of Personhood: Osteobiographical Narratives from Alalakh. En Breathing New Life into the Evidence of Death: Contemporary Approaches to Bioarchaeology, A. Baadsgaard, A. T. Boutin, y J. E. Buikstra (Eds.), pp. 109-133. SAR Press, Santa Fe.

BROWMAN, D. L., 1980. Tiwanaku Expansion and Altiplano Economic Patterns. Estudios Arqueológicos 5: 107-120.

1984. Tiwanaku: Development of Interzonal Trade and Economic Expansion in the Altiplano. En Social and Economic Organisation in the Prehispanic Andes, D. L. Browman, R.L. Burger, and M.A. Rivera (Eds.), pp. 117-142. BAR International Series 194, Oxford. 
BUIKSTRA, J. E., y L. A. BECK, 2006. Bioarchaeology: The Contextual Study of Human Remains. Academic Press, New York.

BUIKSTRA, J. E., y D. UBELAKER, 1994. Standards for data collection from human skeletal remains. Arkansas Archaeological Survey, Fayetteville.

BUIKSTRA, J. E., A. BAADSGAARD y A. T. BOUTIN, 2011. Introduction. En Breathing New Life into the Evidence of Death: Contemporary Approaches to Bioarchaeology, A. Baadsgaard, A. T. Boutin, y J. E. Buikstra (Eds.), pp. 3-26. SAR Press, Santa Fe.

BRIONES, L., y C. CASTELLÓN, 2005. Catastro de geoglifos. Provincia de Tocopilla, Región de Antofagasta. Consejo Nacional de la Cultura y las Artes FONDART, Tocopilla.

BRIONES, L., L. NÚÑEZ y V. G. STANDEN, 2005. Geoglifos y tráfico prehispánico de caravanas de llamas en el desierto de Atacama (norte de Chile). Chungara 37 (2): 195-223.

BROWMAN, D. L., 1974. Pastoral nomadism in the Andes. Current Anthropology 15: 188-196.

BUZON, M. R., J. T. ENG, P. M. LAMBERT y P. L. WALKER, 2005. Bioarchaeological Methods. En Handbook of Archaeological Methods, H. Maschner and C. Chippendale (Eds.), pp. 871-918. Altamira Press, Lanham.

CARTAJENA, I., 1994. Determinación de restos óseos de camélidos en dos yacimientos del Loa Medio (II Región). Estudios Atacameños 11: 25-52.

CASAVERDE, R., 1977. El trueque en la economía pastoril. En Pastores de Puna, J. A. Flores Ochoa (Ed.), pp. 171-192. Instituto de Estudios Peruanos, Lima.

CASES, B., C. REES, G. PIMENTEL, R. LABARCA, D. LEIVA, 2008. Sugerencias desde un contexto funerario en un "espacio vacío" del desierto de Atacama. Boletín del Museo Chileno de Arte Precolombino 13: 51-70.

CRUZ, P., 2009. Tumbas, metalurgia y complejidad social en un páramo del Altiplano surandino. Pulacayo, Bolivia, primer milenio DC. Revista Andina 49: 71-104.

DEMBO, A., y J. IMBELLONI, 1938. Deformaciones intencionales del cuerpo humano de carácter étnico. J. Anesi, Buenos Aires.

DILLEHAY, T., y L. NÚÑEZ, 1988. Camelids, caravans, and complex societies in the south-central Andes. En Recent Studies in PreColumbian Archaeology, N. J. Saunders y O. de Montmollin (Eds.), pp. 603-634. Oxford University Press, Oxford.
EARLE, T., 1991. Paths and roads in evolutionary perspective. En Ancient road networks and settlement hierarchies in the new world, C. Trombold (Ed.), pp. 10-16. Cambridge University Press, Cambridge.

ERICKSON, C., 2000. Los caminos prehispánicos de la Amazonía boliviana. En Caminos precolombinos. Las vías, los ingenieros y los viajeros. L. Herrera y M. C. de Schrimpff (Eds.), pp. 15-42. Instituto Colombiano de Antropología e Historia, Bogotá.

FLORES OCHOA, J. A., 1977. Pastores de Puna. Instituto de Estudios Peruanos, Lima.

GALLARDO, F., L. CORNEJO, R. SÁNCHEZ, B. CASES, A. ROMÁN y A. DEZA, 1993. Una aproximación a la cronología y el asentamiento en el oasis de Quillagua (Río Loa, II Región). Actas del XII Congreso Nacional de Arqueología Chilena 1: 41-60.

GÖBEL, B., 1998. "Salir de Viaje". Producción pastoril e intercambio económico en el noroeste argentino. En 50 años de estudios americanistas en la Universidad de Bonn. Nuevas contribuciones a la arqueología, etnohistoria, etnolingüistica y etnografía de las Américas, S. Daenbach-Salazar Sáenz (Ed.), pp. 867-891. Anton Saurwein, Bonn/Markt Schwaben.

Helms, M., 1992. Long-distance contacts, elite aspirations, and the age of discovery in cosmological context. En Resources, power and interregional interaction, E. Schortman y P. Urban (Eds.), pp. 157174. Plenum Press, Nueva York.

HUBBE, M., C. TORRES-ROUFF, W. A. NEVES, L. M. KING, P. D. A. GLORIA, y M. A. COSTA JUNQUEIRA, 2012. Dental Health in Northern Chile's Atacama Oases: Evaluating the Middle Horizon (AD 500-1000) Impact on Local Diet. American Journal of Physical Anthropology 148: 62-72.

INAMURA, T., 1986. Relaciones estructurales entre pastores y agricultores de un distrito altoandino en el sur del Perú. En Etnografía e historia del mundo andino: Continuidad y cambio, S. Masuda (Ed.), pp. 141-19o. Universidad de Tokio, Tokio.

KNUDSON, K. J., W. J. PESTLE, C. TORRES-ROUFF y G. PIMENTEL, 2012. Assessing the Life History of an Andean Traveller through Biogeochemistry: Stable and Radiogenic Isotope Analyses of Archaeological Human Remains from Northern Chile. International Journal of Osteoarchaeology 22: 435-451.

LARSEN, C. S., 1997. Bioarchaeology: Interpreting behavior from the human skeleton. Cambridge University Press, Cambridge.

LECHTMAN, H., P. CRUZ, A. MACFARLANE, y S. CARTER, 2010. Procesamiento de metales durante el Horizonte Medio en el altiplano surandino (Escaramayu, Pulacayo, Potosí, Bolivia). Boletín del Museo Chileno de Arte Precolombino 15(2): 9-27. 
LECOQ, P., 1987. Caravanes de lamas, sel et échanges dans une communauté de Potosí, en Bolivie. Bulletin de l'Institut Francais d'Etudes Andines 16(3-4): 1-38.

MARROQUIN, J., 1944. El cráneo deformado de los antiguos aimaras. Revista del Museo Nacional 13: 15-40.

McCORMAC, F. G., A. G. HOGG, P. G. BLACKWELL, C. E. BUCK, T. F. G. HIGHAM y P. J. REIMER, 2004. SHCalo4 Southern Hemisphere Calibration o-11.o cal Kyr BP. Radiocarbon 46: 1087-1092.

MURRA, J. V., 1972. El 'control vertical' de un máximo de pisos ecológicos en la economía de las sociedades Andinas. En Visita de la Provincia de León de Huanuco en 1562, vol. 2, J. V. Murra (Ed.), pp. 429-476. Universidad Nacional Hermilio Valdizan, Huanuco.

1985. 'El Archipielago Vertical' Revisited. En Andean Ecology and Civilization: An Interdisciplinary Perspective on Andean Ecological Complementarity, S. Masuda, I. Shimada, y C. Morris (Eds.), pp. 3-14. University of Tokyo Press, Tokyo.

NEVES, W. A., A. M. BARROS y M. A. COSTA JUNQUEIRA, 1999. Incidence and distribution of postcranial fractures in the prehistoric population of San Pedro de Atacama, northern Chile. American Journal of Physical Anthropology 109: 253-258.

NIELSEN, A. E., 1997. El tráfico caravanero visto desde La Jara. Estudios Atacameños 14:339-372.

2001. Ethnoarchaeological perspectives on caravan trade in the south-central Andes. En Ethnoarchaeology of Andean South America: Contributions to archaeological method and theory, L. A. Kuznar (Ed.), pp. 163-201. International Monographs in Prehistory, Ann Arbor.

2006. Estudios internodales e interacción interregional en los Andes Circumpuneños. En Esferas de interacción prehistóricas $y$ fronteras nacionales modernas en los Andes Sur Centrales, H. Lechtman (Ed.), pp. 29-62. Instituto de Estudios Andinos, Lima.

NÚÑEZ, L., 1971. Secuencia y cambio en los asentamientos humanos de la desembocadura del río Loa, en el norte de Chile. Boletín de la Universidad de Chile 112: 3-25.

1976. Geoglifos y tráfico de caravanas en el desierto chileno. En Homenaje al Dr. Gustavo Le Paige, S.J., pp. 147-201. Universidad del Norte, Antofagasta.

NÚÑEZ, L., y T. D. DILLEHAY, 1995 [1979]. Movilidad giratoria, armonía social y desarrollo en los Andes Meridionales: patrones de tráfico e interacción económica (Ensayo). Universidad Católica del Norte, Antofagasta.

NÚÑEZ, L., y A. E. NIELSEN, 2011. En Ruta:Arqueología, Historia y Etnografía del Trafico Surandino. Editorial Brujas, Cordoba.

NÚÑEZ, L., V. ZLATAR y P. NÚÑEZ, 1975. Caleta Huelén-42: una aldea temprana en el norte de Chile (Nota preliminar). Revista Hombre y Cultura, tomo II (5): 67-103.

NÚÑEZ, L., C. AGÜERO, B. CASES y P. DE SOUZA, 2003. El campamento minero Chuquicamata-2 y la explotación cuprífera prehispánica en el desierto de Atacama. Estudios Atacameños 25: 7-34.

PESTLE, W. J., C. TORRES-ROUFF, M. HUBBE, F. SANTANA, G. PIMENTEL, F. GALLARDO y K. J. KNUDSON, Ms. Diversidad en la dieta de poblaciones del norte de Chile a través del estudio de isótopos estables: un primer acercamiento macroregional. Manuscrito en poder de los autores.

PIMENTEL, G., 2006. Arqueología vial. El caso de una ruta de interacción entre el Altiplano Meridional y San Pedro de Atacama. Tesis de magíster en Antropología, Universidad Católica del Norte y Universidad de Tarapacá, San Pedro de Atacama.

2008. Evidencias Formativas en una vía interregional entre San Pedro de Atacama y el Altiplano de Lípez. Estudios Atacameños 35: 7-33.

2009. Las Huacas del Tráfico. Arquitectura ceremonial en rutas prehispánicas del desierto de Atacama. Boletín del Museo Chileno de Arte Precolombino 14 (2): 9-38.

2011. Geoglifos e imaginarios sociales en el desierto de Atacama (Región de Antofagasta, Chile). En Temporalidad, interacción y dinamismo cultural. La búsqueda del Hombre. Homenaje al Profesor Lautaro Núñez Atencio, A. Hubert, J. A. González y M. Pereira (Eds.), pp. 163-200. Ediciones Universitarias, Universidad Católica del Norte, Antofagasta.

2012. Redes viales prehispánicas en el desierto de Atacama. Viajeros, Movilidad e Intercambio. Tesis de doctorado en Antropología. Universidad Católica del Norte y Universidad de Tarapacá, San Pedro de Atacama.

PIMENTEL, G., CH. REES, P. DE SOUZA y P. AYALA, 2010a. Estrategias de movilidad del período Formativo en la Depresión Intermedia, Desierto de Atacama. Actas del XVII Congreso Nacional de Arqueología Chilena, tomo 2: 1353-1364. Ediciones Kultrún, Valdivia. 
PIMENTEL, G., L. NÚÑEZ, CH. REES y M. HUBBE, 2o1ob. Estrategias de movilidad en ejes viales preincaicos que conectaron el Loa medio y la costa de la II Región. Informe Año 1, Proyecto FONDECYT 1090762. Manuscrito en poder de los autores.

PIMENTEL, G., CH. REES, P. DE SOUZA y L. ARANCIBIA, 2011. Viajeros costeros y caravaneros. Dos estrategias de movilidad en el período Formativo del desierto de Atacama, Chile. En Ruta.Arqueología, Historia y Etnografía del Tráfico Sur Andino, L. Núñez y A. E. Nielsen (Eds.), pp. 43-81. Encuentro Grupo Editor, Córdoba.

ROBB, J., 2002. Time and Biography: Osteobiography of the Italian Neolithic Lifespan. En Thinking Through the Body: Archaeologies of Corporeality, Y. Hamilakis, M. Pluciennik y S. Tarlow (Eds.), pp. 153-71. Kluwer Academic/ Plenum, New York.

SANTANA, F., 2011. Multiculturalidad en Cementerio Oriente de Quillagua: Una aproximación desde la bioantropología mediante análisis isotópicos de dieta y movilidad en el curso inferior del río Loa. Período Intermedio Tardio. Memoria de título, Facultad de Antropología y Ciencias Sociales, Universidad de Chile, Santiago.

SAUL, F. P., 1972. The Human Skeletal Remains of Altar de Sacrificios: An Osteobiographic Analysis. The Peabody Museum, Cambridge.

SPAHNI, J.-C., 1967. Recherches archéologiques à l'embouchure du Rio Loa (Côte de Pacifique Chili). Journal de la Société de Américanistes $56(1): 179-251$.

STANDEN, V. G., y B. T. ARRIAZA, 2000. Traumas in the pre-ceramic coastal populations of Northern Chile: Violence or occupational hazards? American Journal of Physical Anthropology 112: 239-249.
STECKEL, R. H., y J. C. ROSE, 2002. The Backbone of History. Cambridge University Press, Cambridge.

STODDER, A. L. W., y A. M. PALKOVICH, 2012. The Bioarchaeology of Individuals. University Press of Florida, Gainesville.

STUIVER, M., P. J. REIMER, y R. W. REIMER, 2005. CALIB 5.0 [www program and documentation].

TORRES-ROUFF, C., 2002. Cranial vault modification and ethnicity in Middle Horizon San Pedro de Atacama, Chile. Current Anthropology 43(1): 163-171.

2007. La deformación craneana en San Pedro de Atacama. Estudios Atacameños 33: 25-38.

2008. The Influence of Tiwanaku on Life in the Chilean Atacama: Mortuary and Bodily Perspectives. American Anthropologist $110(3): 325-337$

TROMBOLD, C. D., 1991. An introduction to the study of ancient New World road networks. En Ancient road networks and settlement hierarchies in the New World, C. D. Trombold (Ed.), pp. 1-9, Cambridge University Press, Cambridge.

WALKER, P. L., 1989. Cranial injuries as evidence of violence in prehistoric southern California. American Journal of Physical Anthropology 80 (3): 313-323.

ZLATAR, V., 1983. Replanteamiento sobre el problema Caleta Huelén 42. Chungara 10: 21-28. 